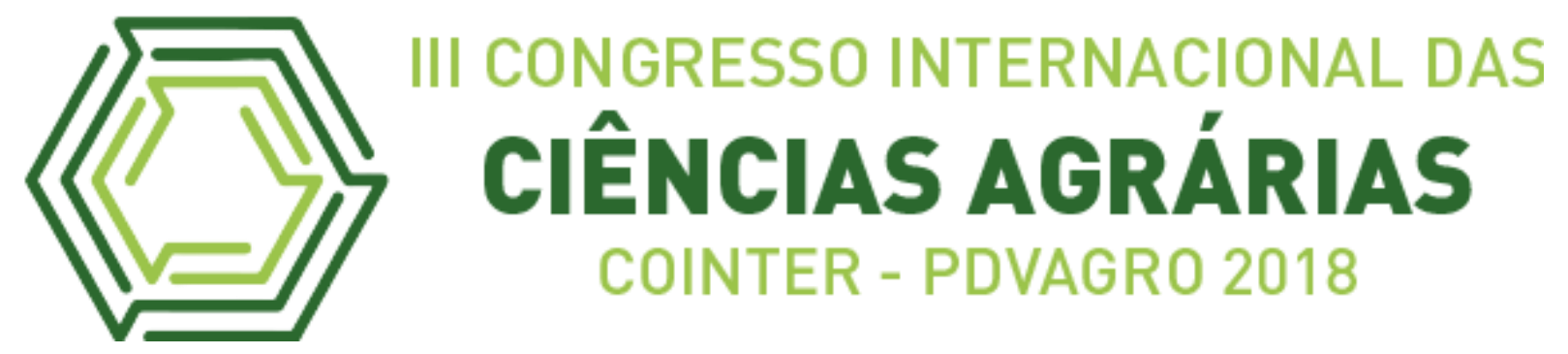

\title{
USO DE EPI E CONHECIMENTO DE CONCEITOS TÓXICOLÓGICOS BÁSICOS PELOS AGRICULTORES DO MUNICÍPIO DE CANHOTINHO-PE
}

\section{USE OF IPE AND KNOWLEDGE OF BASIC TOXICOLOGICAL CONCEPTS BY THE FARMERS OF THE MUNICIPALITY OF CANHOTINHO-PE}

\author{
Apresentação: Pôster
}

\section{Lucas Rodrigues Simões ${ }^{1}$; Gleybson Charles Soares dos Santos ${ }^{2}$; Karla Danielle da Silva} Vieira $^{3}$; Bruna Liedja Lima de Souza ${ }^{4}$; Rita de Cássia Monteiro Batista ${ }^{5}$

\section{DOI: https://doi.org/10.31692/2526-7701.IIICOINTERPDVAGRO.2018.00686}

\section{Introdução}

Com intuito de diminuir perdas na produtividade no meio rural causadas, principalmente, pelo ataque de pragas, doenças e plantas daninhas são utilizados produtos fitossanitários, conhecidos também como agrotóxicos, agroquímicos ou pesticidas (AGÊNCIA NACIONAL DE DEFESA VEGETAL, 2008).

Para garantir a segurança na aplicação dos agroquímicos é essencial o uso correto dos Equipamentos de Proteção Individual (EPIs), sendo estes definidos como todo dispositivo de uso individual com objetivo de proteger a integridade física do trabalhador. Contudo, a utilização incompleta ou até a não utilização do EPI configura um grande perigo à saúde dos aplicadores, aumentando os riscos de intoxicações (NUNES, 2010).

Os produtos e manuais apresentam uma linguagem técnica que é pouco acessível à maioria dos trabalhadores que lidam com estes produtos e os Equipamentos de Proteção Individual (EPI). Além do mais, inúmeras vezes os EPIs não estão adequados à realidade social, cultural, econômica e ao clima que os agricultores brasileiros enfrentam (BEDOR, 2009).

Diante do exposto, o objetivo desse trabalho foi identificar os conhecimentos básicos à cerca da utilização correta dos produtos fitossanitários pelos agricultores da zona rural de

\footnotetext{
${ }^{1}$ Agronomia, UFRPE/Unidade acadêmica de Garanhuns - UAG, lucasrsimoes98@gmail.com

${ }^{2}$ Agronomia, UFRPE/UAG, gleybsoncharles19@gmail.com

${ }^{3}$ Agronomia, UFRPE/UAG, karla.danielle01@gmail.com

${ }^{4}$ Agronomia, UFRPE/UAG, brunalieedja@gmail.com

${ }^{5}$ Engenheira agrônoma, UFRPE/UAG, cassiamonteiro19@hotmail.com
} 
Canhotinho-PE, a partir da aplicação prática dos conceitos elementares de toxicologia e a importância do uso de EPIs na agricultura.

\section{Fundamentação Teórica}

O uso de produtos fitossanitários ou defensivos agrícolas exige a utilização correta dos Equipamentos de Proteção Individual (EPI). Conforme a Norma Regulamentadora Rural n.4, aprovada pela Portaria n. 3.067, de 12 de abril de 1988, do Ministério do Trabalho, os EPI são definidos como todo dispositivo de uso individual destinado a proteger a integridade física do trabalhador (AGOSTINETTO et al., 1998).

Araújo et al. (2000) ao estudarem as práticas de uso de agrotóxicos em plantadores de tomate no Estado de Pernambuco, observaram que 13,2\% dos agricultores já tinham sofrido algum tipo de intoxicação e 64,2\% informaram que não faziam uso de equipamentos de proteção individual (EPI). Teixeira et al. (2014) ao analisar as intoxicações por agrotóxicos de uso agrícola em estados do Nordeste brasileiro, verificou que o Estado de Pernambuco foi o que apresentou mais casos registrados, com 39,5\% das notificações, em seguida os estados do Ceará, Sergipe e Bahia.

\section{Metodologia}

O presente trabalho foi realizado no município de Canhotinho, localizado a uma altitude de 520 metros, a latitude 08 52'38' e a longitude $36^{\circ} 52^{\prime} 38^{\prime \prime}$. Possui uma área de $423,168 \mathrm{~km}^{2}$ e com clima tropical chuvoso com verão seco e apresenta uma temperatura média anual em torno dos $21,8{ }^{\circ} \mathrm{C}$ (CLIMATE, 2017). A população estimada em 2017 é de 24.762 habitantes (IBGE, 2015). A cidade fica à 207,6km de distância da capital pernambucana.

A coleta das informações foi realizada por meio de um questionário semi-estruturado, contendo 8 perguntas sobre conhecimentos elementares de toxicologia, utilização de equipamentos de proteção individual (EPIs) e o destino das embalagens de agrotóxicos.

Foram entrevistados 140 agricultores moradores na zona rural de Canhotinho, no mês de dezembro de 2017. Nenhum dado pessoal (como nome, endereço, telefone ou documentos de identificação) do entrevistado foi registrado.

Os resultados foram devidamente tabulados e expressos em valores reais ou percentuais por meio do programa Excel (Windows 2010). 


\section{Resultados e Discussões}

De acordo com a tabela 1 é possível observar o perfil dos agricultores entrevistados. Em relação ao sexo dos entrevistados, $55 \%$ eram do sexo masculino, e $45 \%$ do sexo feminino. Quanto à faixa etária, a maioria dos entrevistados tinha idade entre 51 e 60 anos, correspondendo a $29,28 \%$ do total dos entrevistados. Referente ao grau de escolaridade, $45 \%$ afirmaram ter o ensino fundamental incompleto, $15,71 \%$ concluíram o ensino médio e nenhum dos entrevistados tinha diploma de ensino superior. De acordo com Soares, Freitas e Coutinho (2005) o baixo nível de escolaridade no campo remete a maiores riscos de exposição aos produtos fitossanitários, uma vez que dificulta a leitura e compreensão dos rótulos, principalmente porque parte das informações contidas nesses rótulos requer conhecimento técnico.

Tabela 1: Dados socioeconômicos dos produtores entrevistados. Fonte: Própria

\begin{tabular}{|c|c|c|}
\hline Entrevistados & $\mathbf{N}^{\mathbf{0}}$ & $\%$ \\
\hline \multicolumn{3}{|l|}{ Sexo } \\
\hline Masculino & 77 & 55 \\
\hline Feminino & 63 & 45 \\
\hline Total & 140 & 100 \\
\hline \multicolumn{3}{|l|}{ Escolaridade } \\
\hline Sem escolaridade & 4 & 2,86 \\
\hline Ens. Fund. Incompleto & 63 & 45 \\
\hline Ens. Fund. Completo & 22 & 15,71 \\
\hline Ens. Med. Incompleto & 14 & 10 \\
\hline Ens. Med. Completo & 37 & 26,43 \\
\hline Ensino superior & 0 & 0 \\
\hline Total & 140 & 100 \\
\hline \multicolumn{3}{|l|}{ Faixa etária (anos) } \\
\hline $18-20$ & 6 & 4,28 \\
\hline $21-30$ & 24 & 17,14 \\
\hline $31-40$ & 28 & 20 \\
\hline $41-50$ & 34 & 24,28 \\
\hline $51-60$ & 41 & 29,28 \\
\hline $61-70$ & 5 & 3,58 \\
\hline$>70$ & 2 & 1,44 \\
\hline Total & 140 & 100 \\
\hline
\end{tabular}


Verifica-se que 63,53\% dos agricultores do município de Canhotinho-PE utilizam agrotóxicos em suas plantações com o intuito de controlar pragas (insetos, fitopatógenos e/ou plantas invasoras) das suas plantações (Tabela 2). Ainda de acordo com a tabela 2, em relação ao uso de EPIs, mais da metade dos entrevistados $(54,3 \%)$ informaram que não fazem o uso dos equipamentos para efetuar a aplicação dos produtos e $15 \%$ declararam o uso ocasional. A não utilização destes equipamentos muitas vezes está ligado a não disponibilidade do empregador, como também a negligência por parte do empregado, principalmente por falta de orientações sobre a importância do uso correto, pelo desconforto provocado pelo calor e em muitos casos por falta de recursos financeiros para comprar os equipamentos de proteção (ARAUJO et al., 2007).

Tabela 2: Perguntas realizadas com os respectivos percentuais das respostas dos entrevistados. Fonte: Própria

\begin{tabular}{|c|c|c|c|}
\hline QUESTÕES & $\operatorname{SIM}(\%)$ & NÃO (\%) & $\begin{array}{c}\text { ÀS VEZES/ } \\
\text { NÃO SEI } \\
\text { INFORMAR }(\%)\end{array}$ \\
\hline $\begin{array}{l}\text { 1. Você utiliza agrotóxicos para o controle de pragas nas } \\
\text { suas plantações? }\end{array}$ & 63,57 & 6,43 & 30 \\
\hline $\begin{array}{l}\text { 2. Você usa os Equipamentos de Proteção Individual } \\
\text { (EPIs) recomendado para utilização de agrotóxico (como } \\
\text { macacão, chapéu ou boné árabe, luvas, máscaras e } \\
\text { óculos) na aplicação dos agrotóxicos na sua lavoura? }\end{array}$ & 30,7 & 54,3 & 15 \\
\hline $\begin{array}{l}\text { 3. Você sabe diferenciar, com relação a classe } \\
\text { toxológica, ou seja, quando o agrotóxico é extremamente } \\
\text { tóxico, altamente tóxico, mediamente tóxico e pouco } \\
\text { tóxico? }\end{array}$ & 4,28 & 95,72 & - \\
\hline $\begin{array}{l}\text { 4. Você lê o rótulo, a bula e o receituário agronômico } \\
\text { antes da aplicação dos agrotóxicos? }\end{array}$ & 3,57 & 94,3 & 2,13 \\
\hline 5. Você coloca a dosagem do produto recomendada? & 86 & 14 & - \\
\hline $\begin{array}{l}\text { 6. Quando você está preparando a calda de agrotóxico ou } \\
\text { aplicando-a, você afasta as crianças, animais e demais } \\
\text { pessoas do ambiente? }\end{array}$ & 97,86 & 0 & 2,14 \\
\hline 7. Qual o destino que você dar as embalagens vazias de & Lixo comum & $\begin{array}{c}\text { Postos de } \\
\text { recolhimento }\end{array}$ & - \\
\hline agrotóxicos? & 66 & 34 & \\
\hline $\begin{array}{l}\text { 8. Na sua cidade tem postos de recolhimento das } \\
\text { embalagens vazias de agrotóxicos? }\end{array}$ & 0 & 92,15 & 7,85 \\
\hline
\end{tabular}


Em relação aos conhecimentos elementares de toxicologia, aproximadamente $96 \%$ dos agricultores alegaram não saber diferenciar as classes toxicológicas, ou seja, quando o produto é extremamente tóxico, altamente tóxico, mediamente tóxico ou pouco tóxico.

Os agricultores quando indagados sobre a prévia leitura do rótulo, da bula e do receituário agronômico, para posterior aplicação dos produtos em suas lavoras, 94,3\% responderam que não realizam a leitura (tabela 2). Contudo, a leitura do rótulo é de extrema importância, pois contém informações sobre a dosagem indicada, uso e lavagens de pulverizadores, o descarte das embalagens, além dos cuidados com o aplicador (SOUZA, 2017). Em relação à aplicação da dosagem indicada, 86\% asseguraram fazer uso apenas da dose recomendada.

Os entrevistados foram questionados sobre o afastamento de crianças, animais e demais pessoas durante o preparo da calda dos agrotóxicos e posteriormente em sua aplicação, por volta de $98 \%$ confirmaram o tal procedimento e $2 \%$ admitiram o afastamento esporádico. Quanto ao destino das embalagens vazias de agrotóxicos $66 \%$ dos agricultores admitiram descarta-las em lixo comum, e quando questionados se em sua cidade existem postos de recolhimento dessas embalagens vazias, nenhum deles afirmou que sim, 92,15\% afirmaram que não, e aproximadamente 7,85\% não souberam informar.

\section{Conclusões}

No município de Canhotinho-PE, 63,53\% dos agricultores entrevistados utilizam agrotóxicos em suas plantações;

Em relação ao uso de Equipamento de Proteção Pessoal, 54,3\% informaram que não fazem o uso desses equipamentos para efetuar a aplicação de agrotóxicos;

Quanto à diferenciação das classes toxicológicas, 96\% dos agricultores alegaram não saber diferenciar pelo rótulo.

\section{Referências}


AGÊNCIA NACIONAL DE DEFESA VEGETAL. Manual de uso correto de equipamento de proteção individual. ANDEF, 2008.

AGOSTINETTO, D.; PUCHALSKI, L.E.A.; AZEVEDO, R.; STORCH, G.; BEZERRA, A.J.A.; GRUTZMACHER, A.D. Utilização de equipamentos de proteção individual e intoxicações por agrotóxicos entre fumicultores do município de Pelotas-RS. Pesticidas Revista Ecotoxicologia e Meio Ambiente, v.8, p.45-56, 1998.

ARAÚJO, A. C. P. et al. Impacto dos praguicidas na saúde: estudo da cultura de tomate. Revista de Saúde Pública, 34(3):309-313, 2000.

ARAUJO, A. J. et al. Exposição múltipla a agrotóxicos e efeitos à saúde: estudo transversal em amostra de 102 trabalhadores rurais, Nova Friburgo, RJ. Ciência \& Saúde Coletiva. Rio de Janeiro, n.1, p. 115-130, 2007.

BEDOR, C. N. G.; RAMOS, L. O.; PEREIRA, P. J.; RÊGO, M. A. V.; PAVÃO, A. C; AUGUSTO, L. G. S. Vulnerabilidades e situações de riscos relacionados ao uso de agrotóxicos na fruticultura irrigada. Rev. bras. epidemiol. 12(1):39-49, 2009.

CLIMATE. Clima de Canhotinho. Disponível em: $<$ https://pt.climatedata.org/location/43049/>

IBGE. Diretoria de Pesquisas - DPE - Coordenação de População e Indicadores sociaisCOPIS, 2015

NUNES, G. C. Uso do EPI - Equipamentos de Proteção Individual nas pequenas propriedades rurais produtoras de fumo no município de Jacinto Machado-SC. [Dissertação]. Criciúma (SC): Universidade do Extremo Sul Catarinense, 2010.

SOARES, W. L.; FREITAS, E. A. V.; COUTINHO, J. A. G. Trabalho rural e saúde: intoxicações por agrotóxicos no município de Teresópolis- RJ. Revista de Economia e Sociologia Rural, Rio de Janeiro, n. 4, p.685-701, 2005.

SOUZA, J. P.; FARIA, H. A.; PEREIRA, R. S. F. Uso de agrotóxico pelos trabalhadores rurais do município de Crisópolis-BA. Estação Científica (UNIFAP), Macapá, v. 7, n. 3, p. 107-117, 2017

TEIXEIRA, J. R. B. et al. Intoxicações por agrotóxicos de uso agrícola em Estados do Nordeste brasileiro, 1999-2009. Epidemiologia e Serviço de Saúde, Brasília, v. 23, n. 3, p. 497-508, 2014. 